\title{
MEASUREMENT OF SUPERVOLTAGE X-RAYS WITH THE FREE-AIR IONIZATION CHAMBER
}

\author{
By Lauriston S. Taylor, George Singer, and Arvid L. Charlton
}

\section{ABSTRACT}

A free-air ionization chamber for the measurement of supervoltage X-rays is described. It is built on the guarded-field principle and of such size as to permit measurements for X-ray excitation voltages from 150 to $350 \mathrm{kv}$ at atmospheric pressure and $200 \mathrm{kv}$ upward at elevated pressures. The electrode system is contained in a pressure cylinder of such size as to give an equivalent plate spacing of $4 \mathrm{~m}$ at a pressure of $10 \mathrm{~atm}$. The chamber characteristics have been studied in the range of 200 to $400 \mathrm{kv}$. The most important finding is the required increase in plate separation at the higher voltages. While reasonable, this is at variance with the findings of other workers. From the measurement of the plate separation for full electronic equilibrium, electron ranges may be obtained.

To carry out these measurements it was necessary to design and construct a high-voltage plant capable of extreme steadiness of operation. This was accomplished with a four-stage rectifier having valves operated on a single pumping system. Potentials were carefully distributed through the system with the result that the voltage could be measured and controlled within $\pm 1 / 4$ percent, which figure also represents the variation in tube output.

The X-ray tube is of the simple four-stage type, made up of Pyrex-glass cylinders. By means of an insulated target, only the target current is measured.

\section{CONTENTS}

I. Introduction $\ldots \ldots$

II. High-voltage equipment and X-ray tube

1. General requirements_.................. 22

2. Rectifier circuit

3. Pumping system.

4. X-ray tube_.......... 24

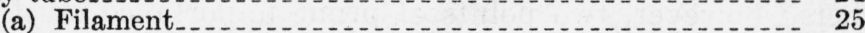

(b) Target........ 25

(c) Focusing .................... 28

(d) Distribution of current in the X-ray tube........ 29

5. Voltage control and measurement.................. 29

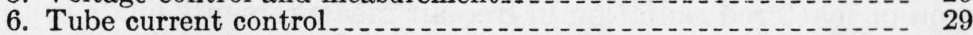

III. Standard free-air ionization chamber

1. Pressure chamber.

2. Electrode system

3. Field correction

4. Stray ionization

5. Diaphragms

6. Saturation voltage

IV. Current measurements _........

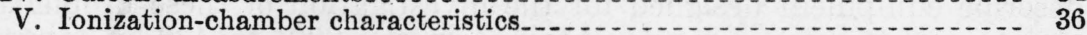

1. Field distortion

2. Scattering from diaphragm and pressure-chamber ends....... 37

3. Plate separation ............ 39

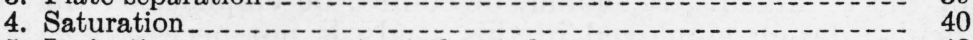

5. Ionization measurements at elevated pressures.................... 42

6. Inverse-square law

VI. General conclusions.

VII. References . 


\section{INTRODUCTION}

The internationally accepted definition of the unit of X-ray quantity has from the first been based upon the ionization produced in a unit volume of unrestricted air [1]. ${ }^{1}$ The original definition was, in fact, a statement of the physical requirements for reproducing a unit in terms of the ionization in a free-air ionization chamber. This unit has served its purpose very well for the X-ray voltages in use up to within the past 3 or 4 years. However, with excitations in excess of $200 \mathrm{kv}$, various mechanical and physical difficulties have appeared to limit the applicability of the definition, as well as of the free-air ionization chamber used to determine it.

Consequently, there has been an increasing trend toward the use of thimble chambers for the fundamental realization of the roentgen. The theoretical as well as experimental evidence favoring this trend appears to be reasonably sound, particularly as regards theory. Experimentally the problem has presented great difficulties which, in the hands of a few experimenters, seem to have been adequately overcome. There remains, even for them, the problem of definitely and irrefutably tying together the thimble-chamber measurements in the supervoltage region with free-air measurements in the highvoltage region. The thimble-chamber measurements appear to be self-consistent, but it is definitely desirable to check them by a wholly independent means and at the same time correlate them with the free-air measurements at the lower voltages.

In order to validate thimble-chamber measurements in the supervoltage region it has been necessary to redefine the roentgen. This was done at the Fifth International Congress of Radiology [2] as follows: "The roentgen shall be the quantity of $\mathrm{X}$ or gamma radiation such that the associated corpuscular emission per 0.001293 gram of air produces, in air, ions carrying 1 e. s. u. of quantity of electricity of either sign." It is not proposed to discuss this definition in its relation to thimble chambers; it has already been ably done by Mayneord [3, 4], Lauritsen [5, 6, 7], Gray [8, 9, 10], Laurence [11], Failla [14], and others. In connection with the use of free-air chambers, ${ }^{2}$ however, two points of prime importance must be mentioned. First, the physical magnitude of the unit is exactly the same as in the older definition for excitations below about $200 \mathrm{kv}$ (peak). Second, the new definition removes the question of inclusion or exclusion of scattered radiation in free-air measurements made in the supervoltage region-a question which had been troubling the American X-ray standardization committees for some years [12]. The new definition therefore makes it possible and desirable to extend the useful range of the free-air chamber up to indefinitely high voltages, provided the design characteristics can be adequately worked out in conformity with the definition. It is the purpose of this paper to describe equipment designed for the investigation of these problems and to report measurements obtained in the $200-$ to $400-\mathrm{kv}$ range, designed to test the conditions essential for realizing the definition of the roentgen. It should, of course, be emphasized that the particular design employed in this study is not necessary in all cases,

1 Numbers in brackets refer to the citations listed at the end of this paper.

2 "Free-air" ionization chambers may be classed roughly as those in which chamber walls contribute nothing to the measurement. This may, of course, include chambers operated above atmospheric pressure. 
but was so chosen as to yield the design factors for any particular voltage range desired.

We will review very briefly the several investigations of free-air ionization chambers for the measurement of supervoltage or gamma radiations, and point out what appears to us to be the limitations of each of these several studies insofar as relates to X-ray measurements.

The first free-air chamber for extra-hard radiations was constructed by Failla [13] in 1931. This had a maximum plate separation of about $1 \mathrm{~m}$ and a length of about $1.5 \mathrm{~m}$. Field correction was provided by means of the guard-wire principle such as developed for our lower-voltage chambers [15]. Because of size limitations this chamber did not prove successful in the measurement of gamma rays. Failla was also unable to use it with X-ray voltages above $200 \mathrm{kv}$ since the available treatment room was too small.

Mayneord [16] and his coworkers (1934) constructed a parallelplate ionization chamber having a maximum plate separation of 20 $\mathrm{cm}$ and plate length of $50 \mathrm{~cm}$. For this a field correction was found unnecessary. Their results indicated that a plate separation of 20 cm was sufficient for X-ray potentials up to $400 \mathrm{kv}$, and apparently also for gamma rays. However, as the measurements with this chamber showed marked divergences from the thimble-chamber measurements above $250 \mathrm{kv}$ they discarded the parallel-plate chamber as a primary standard. They gave insufficient distance between limiting diaphragm and collector as one of the main design limitations affecting the attainment of radiation equilibrium in the ionized volume.

Lauritsen [5] used a parallel-plate chamber for voltages up to 900 $\mathrm{kv}$. With a plate separation of $30 \mathrm{~cm}$, radiation equilibrium was apparently obtained by placing the chamber at a considerable distance from the limiting diaphragm and using a very narrow beam of radiation. No direct evidence for the adequacy of the $30-\mathrm{cm}$ plate spacing was given. In a personal communication he showed a Wilson cloudexpansion photograph of a narrow 700-kv X-ray beam wherein the tracks appeared to be limited to a region about $10 \mathrm{~cm}$ on both sides of the beam. No data were given tying directly his supervoltage measurements to high- or low-voltage measurements.

Jaeger [17] has reported on the use of the PTR Fasskammer at voltages up to $500 \mathrm{kv}$, and shows perfect agreement with his "Universalkammer" for X-ray voltages from 10 to $500 \mathrm{kv}$. His free-air chamber is $25 \mathrm{~cm}$ in diameter, with the collecting electrode parallel to and about $4 \mathrm{~cm}$ from the axis and the collimated X-ray beam. Using lining sleeves of different diameters placed in this chamber, he apparently proves its size to be adequate. This conclusion is very difficult to reconcile with our finding that a $12-\mathrm{cm}$ plate spacing is just barely sufficient for the measurement of $180-\mathrm{kv} \mathrm{X}$-rays.

Kaye and Binks $[18,19]$ have described a large free-air ionization chamber also employing the guarded-field principle and having a plate spacing of some $3 \mathrm{~m}$, which they used for measuring gamma rays. They have not reported any measurements with X-rays.

Of these various studies, Mayneord's [16] and Jaeger's [17] appear to be the most complete and yet their essential results are contradictory. We have endeavored therefore to set up an experimental arrangement which permits the overlapping of the conditions of their investigations. 


\section{HIGH-VOLTAGE EQUIPMENT AND X-RAY TUBE}

\section{GENERAL REQUIREMENTS}

For the investigation outlined above, as well as to provide suitable equipment for future standardization work, it seemed advisable to construct a special tube and voltage-rectifying system containing certain features conducive to the elimination of some of the uncertainties present in earlier work.

The principle requirements were: (1) A small and steady focal spot, (2) a very steady tube voltage and current, (3) a reasonably small ripplage, (4) a minimum of filtration between the target face and ionization chamber, and (5) as large a distance between target and chamber as might be necessary.

\section{RECTIFIER CIRCUIT}

The electric circuit shown in figure 1 is a simple cascade of four halfwave rectifiers designed to give $150 \mathrm{kv}$ (constant) each. Successive units above the first were supplied through 1:1 insulation transformers

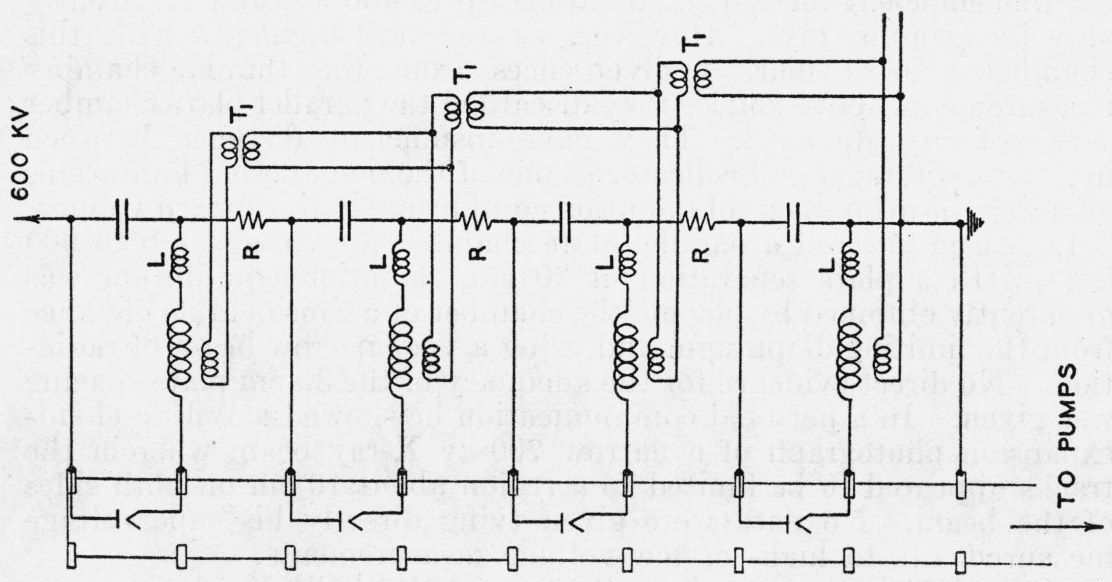

Figure 1.-Schematic diagram of 600-kv d-c. rectifier system.

$\left(T_{1}\right)$, of the toroidal type having only oil insulation. Each unit was connected to its neighbor through 0.5 -megohm (Glo-bar) noninductive resistors $(R)$. The main transformers were isolated from the remainder of the circuit by small radio-frequency chokes $(L)$, each made up of $2 \mathrm{lb}$ of size $6 \mathrm{AWG}$ copper wire wound on a 2 -in. Bakelite tube.

Each $150-\mathrm{kv}$ unit was placed on a wood frame supported on porcelain insulators.

Galvanized-iron "down spouting" was used for most of the conductors above $150 \mathrm{kv}$. Otherwise, little precaution was made for the avoidance of corona. Mutual shielding of many of the components apparently helped because at $400 \mathrm{kv}$, corona was neither excessive nor troublesome.

The filaments of the four rectifiers were supplied by four $1: 1,15-\mathrm{v}$ insulation transformers (T2) connected in series and resting atop the main transformers (T3) as shown in figure 2. The rectifier tubes were made for continuous evacuation by a single apiezon oil-diffusion 


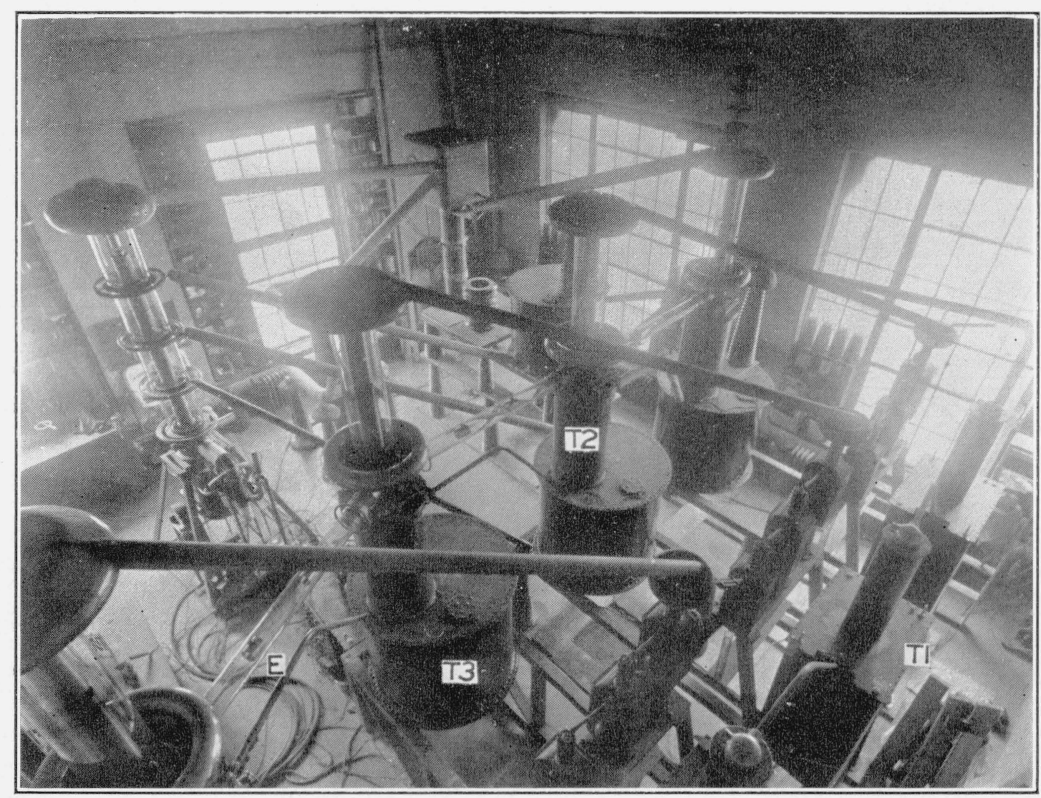

FiguRE 2.-Rectifier system and X-ray tube, looking down from one corner of the room. 


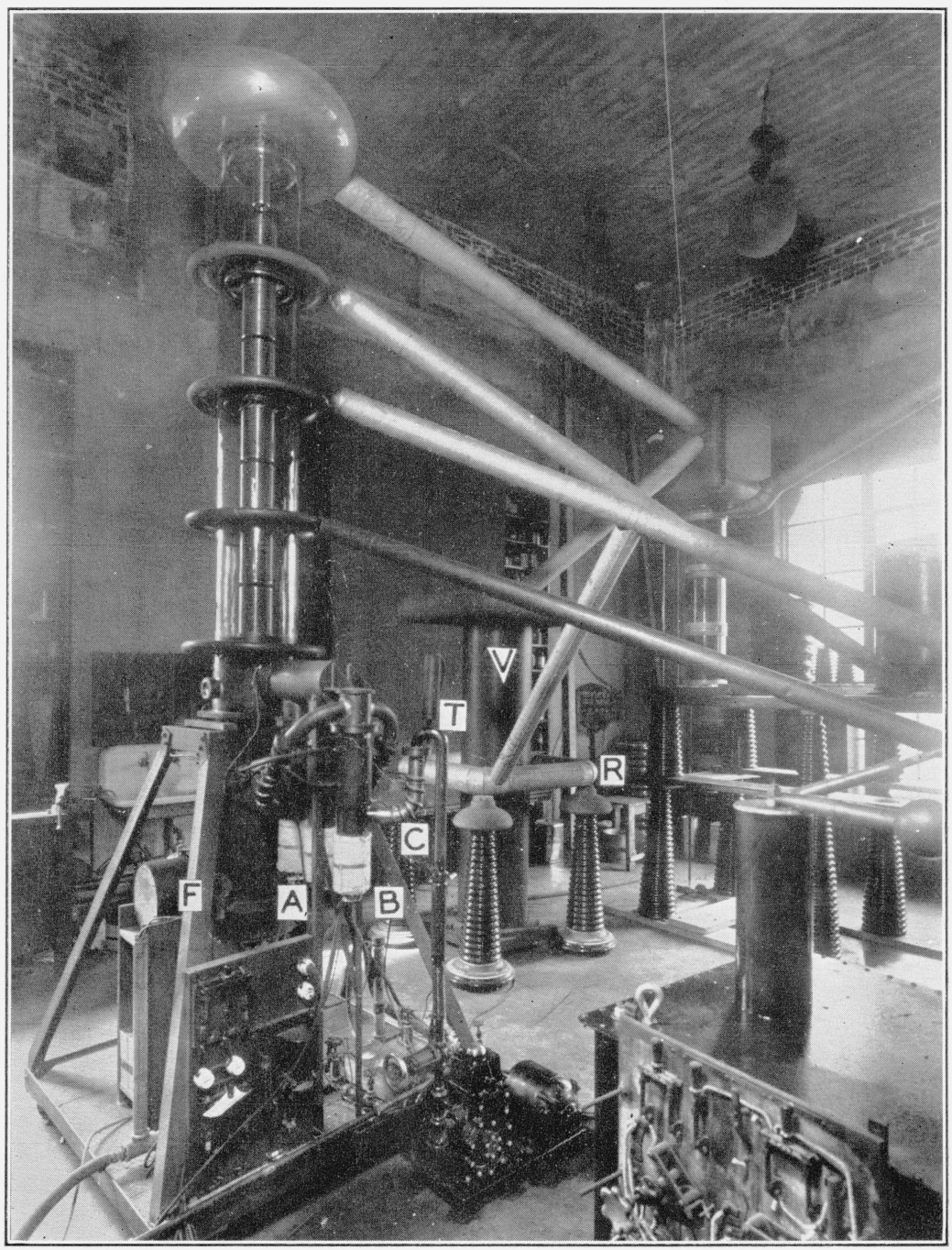

Figure 4.-X-ray tube and voltmeter $(V)$. 
pump system [20]. Tubes of 8 -in. Pyrex glass $40 \mathrm{in}$. long served as the envelope for each rectifier, which was designed for a maximum inverse voltage of $300 \mathrm{kv}$. Each electrode consisted of a 4-in. brass tube ending with a $1 / 2$-in. diameter reentrant steel beading. The filaments ( $F$, fig. 3 ) made up of $134 \mathrm{~mm}$ of 15 -mil tungsten, were each

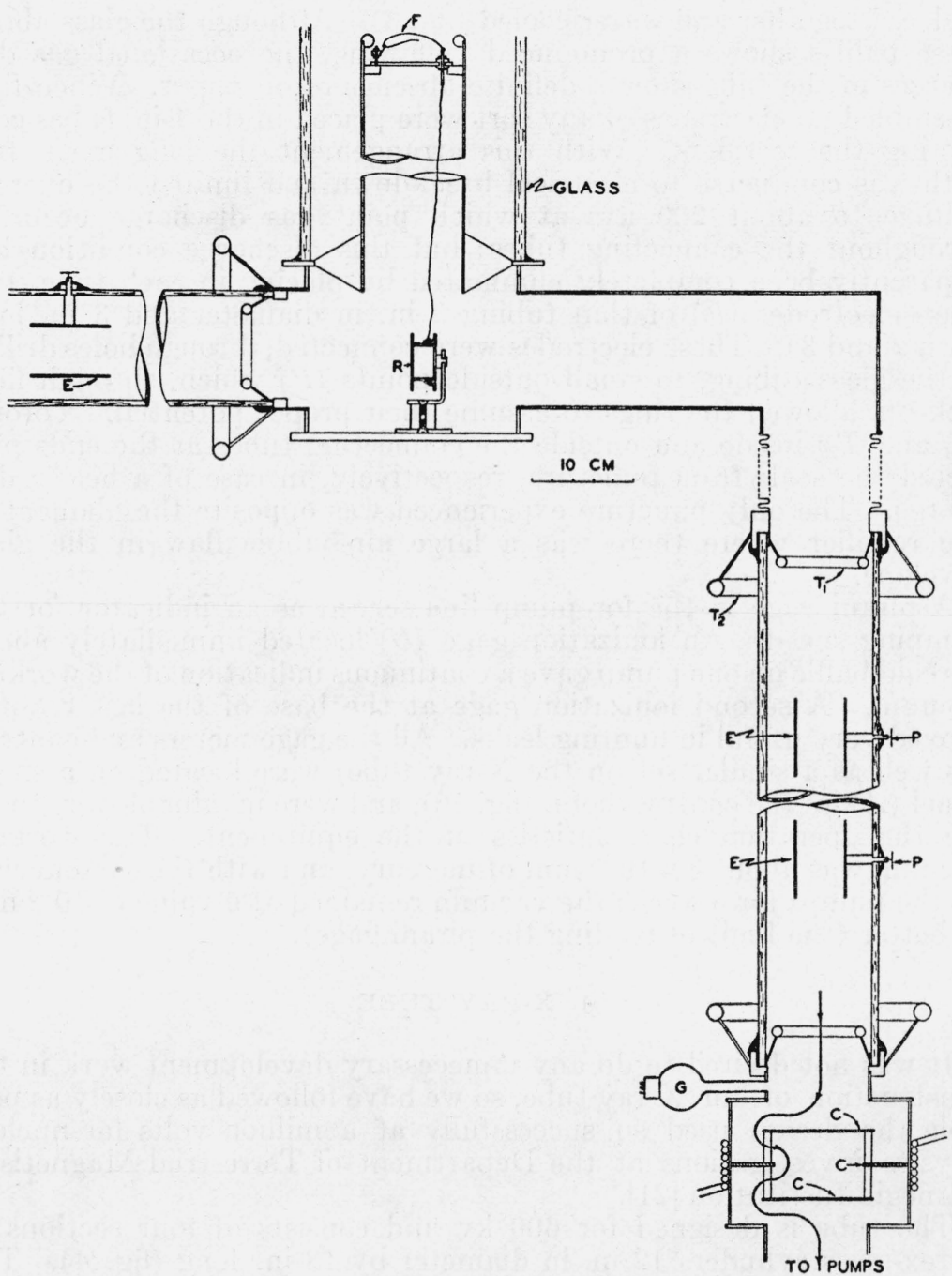

FigURE 3.-Cross sections through the pump baffles and the manifold of the first rectifier tube

bent in two open loops toward the anode but not extending beyond the plane of the end of the cathode. Operating characteristics showed a space current of about $20 \mathrm{ma}$ at $1,000 \mathrm{v}$, for a filament current of 10.7 amp. The filaments could be readily removed for replacement, by removing a waxed-on cover and reaching through the anode from the top of the tube. One filament lead was fastened to the electrode and the other to a self-winding reel $(R)$ at the bottom of the manifold. 


\section{PUMPING SYSTEM}

The pumping system consisted of two 4-in. "fine" apiezon oil pumps feeding into a third "coarse" pump and all backed up by a Cenco Hypervac-20 pump. Baffles between the fine pumps and the glass system consisted of alternate copper rings $(C)$ and disks, all soldered together and water cooled (fig. 3). Although the glass above these baffles shows a pronounced yellowing, the occasional gas discharges in the tube show a definite absence of oil vapor. When first assembled no electrodes of any sort were placed in the 4-in. tubes connecting the rectifiers. With this arrangement the long mean free path was conducive to electrical breakdown and limited the over-all voltage to about $200 \mathrm{kv}$, at which point gas discharge occurred throughout the connecting tubes; but this discharge condition has apparently been completely eliminated by placing in each tube, two brass electrodes $(E)$ of thin tubing 2 in. in diameter and 3 in. long (figs. 2 and 3). These electrodes were connected, through holes drilled in the glass tubing, to small outside points $(P)$ which, through field pick-up, allowed the rings to assume their proper potential. Toroids $\left(T_{1}\right.$ and $\left.T_{2}\right)$ inside and outside the connecting tubes at the ends protected the seals from puncture, respectively, in case of a heavy discharge. The only puncture experienced was opposite the filament of one rectifier where there was a large air-bubble flaw in the glass envelope.

A pirani gage in the forepump line served as an indicator for the pumping speed. An ionization gage $(G)$ located immediately above the cold baffle on one pump gave a continuous indication of the working vacuum. A second ionization gage at the base of the last rectifier proved very useful in hunting leaks. All the gage meters and controls (as well as a similar set on the X-ray tube) were located on a single panel $(A)$ in the control room, (fig. 10), and were invaluable for studying the operation characteristics of the equipment. The working vacuum was about $3 \times 10^{-6} \mathrm{~mm}$ of mercury, and with the system shut off the pumps for 6 weeks the vacuum remained at a value of $10^{-3} \mathrm{~mm}$ or better (the limit of reading the pirani gage).

\section{X-RAY TUBE}

It was not desired to do any unnecessary development work in the construction of our X-ray tube, so we have followed as closely as possible the design used so successfully at a million volts for nuclear physics investigations at the Department of Terrestrial Magnetism, Carnegie Institution [21].

The tube is designed for $600 \mathrm{kv}$ and consists of four sections of Pyrex-glass cylinders 12 in. in diameter by 18 in. long (fig. 4). The electrodes were 5 in. in diameter with reentrant rolled-steel ends. Adjacent accelerating tubes were separated by a $\frac{1 / 2}{2}$-in. gap. Following Tuve [21], these electrodes were very accurately aligned during assembly by means of a long mandrel. The glass cylinders and electrodes were assembled on the floor and held in place with tie rods while the wax (Pizein) joints were made. The resulting unit was then lifted into place atop the pump manifold, the tie rods being kept taut until after the tube was evacuated. They were always replaced before letting air into the system. While this procedure caused a little more 
trouble than with direct assembly (as first tried), it eliminated troublesome cracking of the seals from unavoidable strains.

The pumping system for the X-ray tube is somewhat faster than that used, for the rectifiers, since it was possible here to eliminate some of the long delivery tubes. The arrangement of the two fine pumps $(A)$ and one coarse pump $(B)$ is shown in figure 4 . The use of toilet bends $(C)$, sink traps $(T)$, etc., eliminated many soldered joints, as is evident from the figure. All pump connections were made with the rubber gasket seals described by Rose [39]. The pressure gages duplicated those of the rectifier system and were read at the same panels.

All operating components of both tube and rectifier were protected by an electrical interlock system to prevent errors in operation. This insured the following starting order: (1) Forepump, (2) water supply, (3) pump heaters, and (4) transformer voltage. A failure of any one would cut off all higher components and necessitate manual resetting.

\section{(a) FILAMENT}

The filament construction is essentially of the cup focusing type shown in figure 5. Provision is made for complete adjustment while the tube is in operation. The main filament housing $(A)$ is made of thin steel tubing, $2 \frac{1}{2}$ in. in diameter, extending down nearly to the center of the first glass section. Facing the filament cup is the first accelerating electrode $(B)$, a flared steel tube of about the same diameter. The filament is supported on a Lavite bushing $(L)$, which may be centered by means of the setscrews $(C)$. Filament leads are insulated from the main housing to permit the use of biasing potentials if necessary. Vertical adjustment of the filament assembly of about $1 \mathrm{~cm}$ is effected with an external pulley $(P)$, the displacement being provided for by a Sylphon bellows $\left(S_{1}\right)$. A lateral adjustment up to $1 \mathrm{~cm}$ from the center in any direction is effected with a double ballbearing eccentric, as described by Tuve [22], the seal being secured with the Sylphon bellows $\left(S_{2}\right)$.

The total distance from filament to target is about $8 \mathrm{ft}$. and within this path appreciable deflection of the cathode beam may be produced by the earth's magnetic field. This becomes very troublesome at the lower voltages. It was eliminated by lining the accelerating tubes with a double layer of 0.014-in. heat-treated Chrome Permalloy.

\section{(b) TARGET}

The target construction is shown in figure 6 . The most essential feature is its complete insulation by means of a glass gasket $(G)$ to permit the use of a milliammeter in the ground circuit. The target $(T)$ is of lead, electroplated on copper and mounted at the bottom of a brass tube $1 / 8$-in. thick and 5 -in. in diameter in the manner described by Folsom [23]. At the point of emergence $\left(W_{1}\right)$ of the X-ray beam, this tube was milled down to a uniform thickness of about $1 / 32$ in. Surrounding the entire target tube is a 6 -in. water jacket. This is provided with a reentrant window $\left(W_{2}\right)$ (opposite the target window $W_{1}$ ) covered with $1 / 64$-in. brass and extending in so as to nearly touch $W_{1}$. Thus the total inherent filtration of the tube consists of $3 / 64$ inch of brass plus about $2 \mathrm{~mm}$ of water.

Extending down into the target tube, and spaced $1 / 8$ in. from it, is a thin steel tube $(L)$, which is insulated from both ground and the 
target. This shield tube is connected with the control room and serves three purposes: (1) It prevents the bulk of the scattered electrons from striking the target tube, so that the milliammeter $\left(M_{1}\right)$ gives very nearly the true target current; (2) it permits the

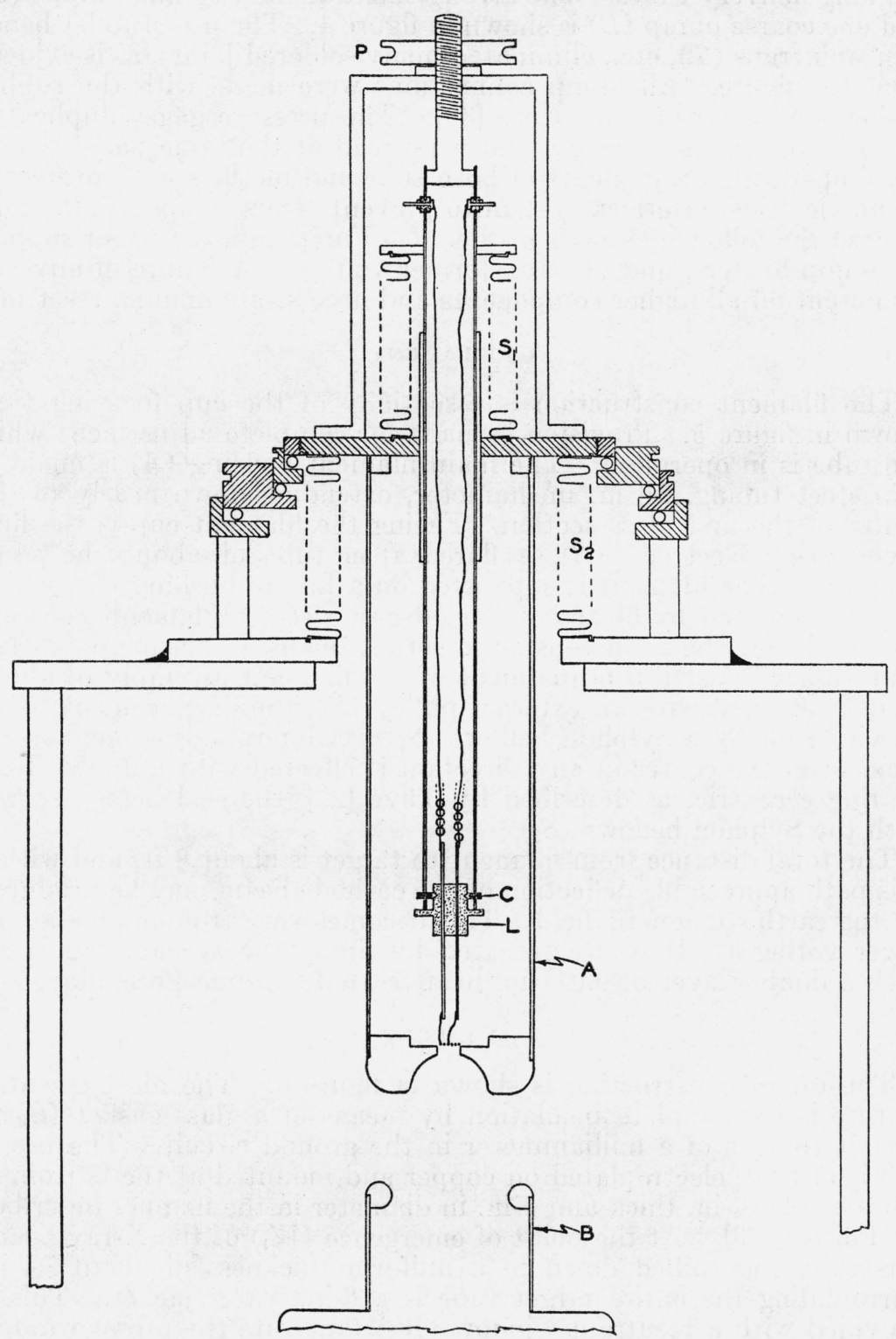

Figure 5.-Filament assembly.

remote reading of the current to the shield and thus allows adjustment of the focusing conditions to obtain the optimum ratio of $M_{1}$ to $M_{2}$; and (3) it operates through a sensitive relay $(R)$ to open the circuit-breakers in the transformer circuit in case of a general gassy 


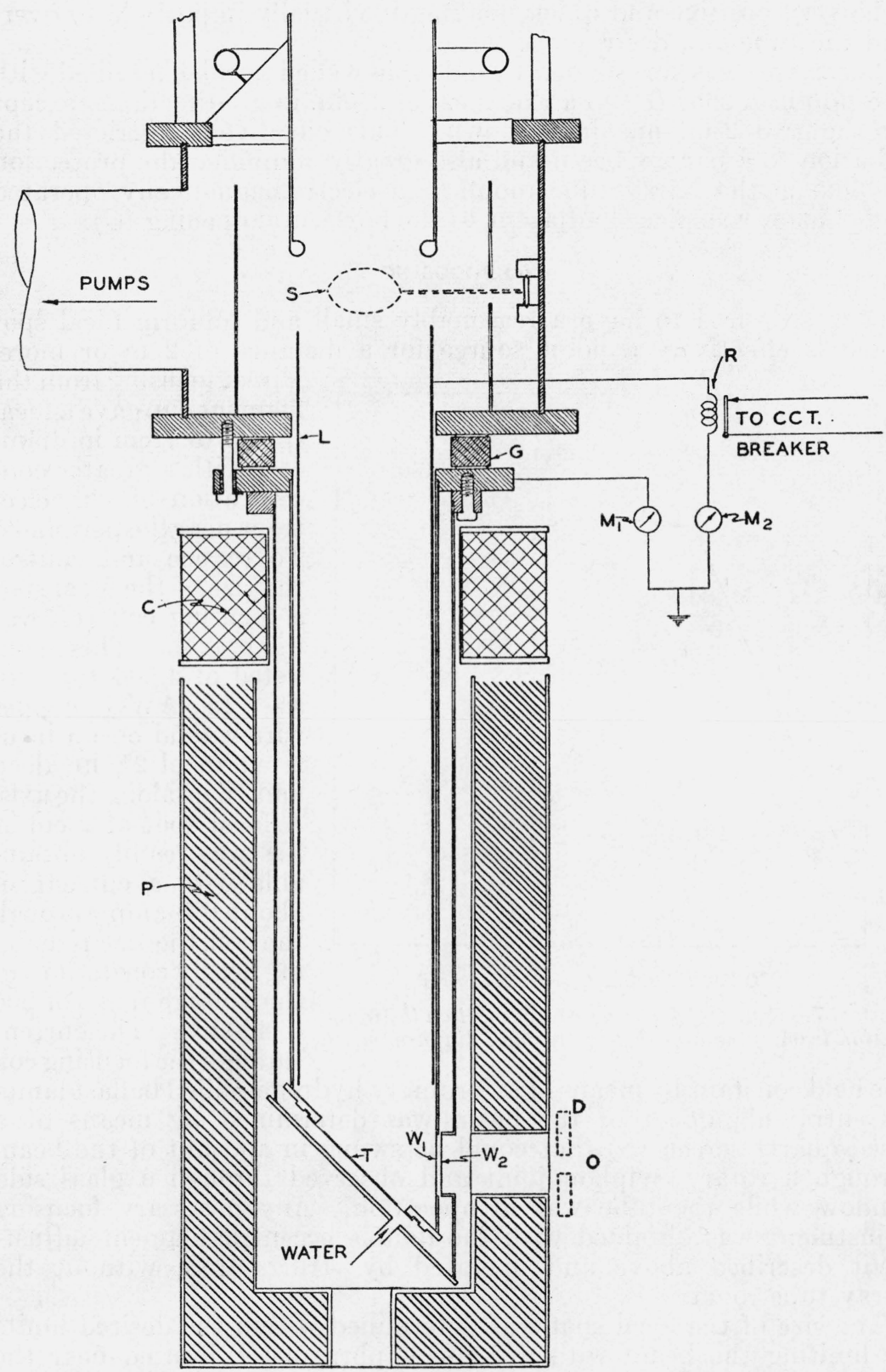

FiguRE 6.-Cross section through the earthed end of the $X$-ray tube, showing target. details, focusing coil, etc.

condition of the tube. This last result is brought about by the fact that the presence of a general "gassy" condition throughout the tube defocuses the electron beam, causing it to strike the shield and pass a releasing current through the relay circuit. This action was found 
to be very positive and quick, making it virtually impossible to overload the tube and destroy the target.

The target was surrounded by a double-walled iron jacket filled with $1.15-\mathrm{mm}$ lead shot $(P)$ to a thickness of $2 \frac{1}{2}$ in. in all directions, except for the two 2-in. openings shown. This effectively restricted the radiation to a narrow beam and also greatly simplified the protection problem in the X-ray tube room. An electromagnetically operated lead shutter was placed adjacent to the horizontal opening $(O)$.

(c) FOCUSING

It was desired to have a reasonably small and uniform focal spot which is effectively a point source for a distance of $2 \mathrm{~m}$ or more.

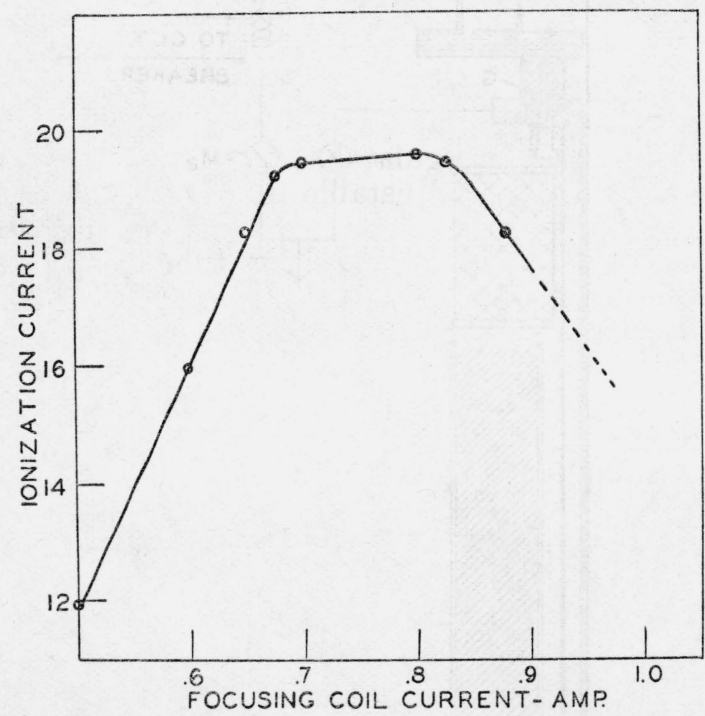

FIGURE 7.-Effect of focusing coil current on the radiation leaving the tube through a small diaphragm. Direct focusing from the filament cup gave a focal spot 5 to $7 \mathrm{~cm}$ in diameter with a greater concentration of the electrons near the periphery. To reduce and control the size of the focal spot a focusing coil $(C)$ was used [24]. This consisted of 4,500 turns of size 18 AWG copper wire wound on an insulated spool $2 \frac{3}{4}$ in. deep and $3 \frac{3}{4}$ in. along the axis. A focal spot of $2 \mathrm{~cm}$ or less was readily obtainable with a current of about 0.7 amp through the coil, the size remaining nearly constant over the voltage range of 200 to $400 \mathrm{kv}$. The current through the focusing coil was held constant by means of an ordinary hydrogen-filled ballast lamp.

Central alignment of the beam was determined by means of a fused-quartz screen $(S)$ that could be swung in and out of the beam through a rotary Sylphon joint and observed through a glass side window while the tube was in operation. Any necessary focusing adjustment was obtained with the double eccentric-filament adjustment described above and operated by strings from without the $\mathrm{X}$-ray tube room.

The size of the focal spot was determined within the desired limits by limiting the beam with a $3-\mathrm{cm}$ diaphragm $(D)$ located near the target, and then measuring the X-ray output with an ionization chamber some $3 \mathrm{~m}$ away. Figure 7 gives a typical curve of the ionization current as a function of the current in the focusing coil. The flat peak shows that the focal spot did not overlap the temporary diaphragm and hence was of somewhat less diameter. Numerous pin-hole photographs verified these conditions and also showed a negligible amount of off-focus radiation. For normal operation a focusing-coil current at the peak of the curve was employed. 


\section{(d) DISTRIBUTION OF CURRENT IN THE X-RAY TUBE}

Simultaneous measurements of the target current, shield current, and current input to the high side of the tube gave a further check on the completeness of the focusing. In all cases the sum of the target and shield currents equalled the total input current within the limits of accuracy of the meter readings. Also the target current bore a very nearly constant ratio of about $4: 1$ to the shield current for all voltages and tube currents used. To test for secondary radiation arising from scattered electrons striking the ends of the accelerating tubes, a pin-hole X-ray exposure of the entire tube was made; but an hour's exposure failed to reveal any image on the film.

\section{VOLTAGE CONTROL AND MEASUREMENT}

Input voltage for the main transformers is supplied by a $25-\mathrm{kva}$ 60-cycle generator driven by a 40-hp synchronous motor. The generator voltage was applied directly to the transformers with essentially no resistance in the line. Voltage was regulated through field rheostats located in the control room, and adjustable in steps as small as $.02 \mathrm{ohm}$ out of a total of about $50 \mathrm{ohms}$.

Output voltage was measured directly at the X-ray tube terminal with a $600-\mathrm{kv}$ resistance voltmeter (V), as described by Tuve [25] (fig. 4). The resistance elements and corona shields are contained in a vertical Bakelite tube sealed to prevent the entrance of moisture. To assist in obtaining a uniform potential gradient along the Bakelite tube, a potential ring $(R)$ is placed about its center and connected to the midpoint of the voltage cascade.

The resistance was calibrated under full working conditions against our standard $200-\mathrm{kv}$ shielded resistance voltmeter [26], which has an over-all accuracy of $\pm 1 / 4$ percent or better. To do this, the 600 $\mathrm{kv}$ resistor was tapped off at intervals corresponding to $200 \mathrm{kv}$, and compared directly with the standard up to that voltage. Repeated checks have shown the resistor to be reliable within the desired limits of accuracy $( \pm 1 / 3$ percent).

\section{TUBE CURRENT CONTROL}

The X-ray tube filament is heated with storage batteries located in a corona shield atop the last voltage cascade. A coarse handoperated rheostat gives a preliminary current setting. Fine control is effected by two remotely operated motor-driven rheostats of which one gives a continuous adjustment over a range of about $0.1 \mathrm{ohm}$, and the other an adjustment over a range of $0.8 \mathrm{ohm}$ in 25 steps. Readings of the tube current were made with a milliammeter $\left(M_{1}\right)$ (fig. 6). For control purposes a galvanometer with a displaced zero is used which renders the current easily controllable within $1 \mathrm{ma}$ in about 1,000 ma.

Occasional variations of 1 or 2 percent in output were noted in spite of apparently steady tube current and voltage. These changes usually took place after a slight gassing or other disturbance and were no doubt caused by a slight change in the focal spot.

To eliminate this a multiplate-control ionization chamber ( $F$, fig. 4 ) was placed in the beam immediately next to the shutter. The tube current was adjusted to hold the control ionization current steady 
at a given value of the tube voltage. By this means it is possible to hold the radiation output constant within $\pm 1 / 4$ percent over the period of a whole day. It is observed that, using this method of control, the target current does not depart from its steady value by more than 1 or 2 percent.

\section{STANDARD FREE-AIR IONIZATION CHAMBER}

After reviewing the investigations outlined in the introduction, it was felt that no one of them offered the best solution to the problem of establishing a free-air standard X-ray ionization chamber. One of the principal difficulties was judged to be the inadequacy of the methods of comparison with accepted standards in other voltage ranges.

\section{PRESSURE CHAMBER}

It was decided to construct a chamber to operate under a moderate air pressure, thereby reducing operating dimensions to practicable magnitudes. The need was a single ionization chamber capable of measuring X-rays in roentgens, under the following conditions: (1) At elevated pressures X-rays from $200 \mathrm{kv}$ upward; (2) at atmospheric pressure X-rays from $300 \mathrm{kv}$ downward; and (3) at such plate separations that field correction is unnecessary. It was also necessary to be able to determine air absorption corrections under all operating conditions.

The completed ionization chamber consists of a steel pressure cylinder $30 \mathrm{in}$. in diameter and $7 \mathrm{ft}$ long (inside). The rear end is completely removable (figs. 8 and 9). Air is pumped in through a calcium chloride drier, and in addition several trays of drier are kept in the cylinder. Temperature within the chamber is measured with a thermometer fastened to the electrode assembly and read through a thick glass window at the rear.

The pressure is read and controlled from a multiple mercury manometer $(B)$, as described by Meyers and Jessup [27], located in the control room (fig. 10). The manometer tubes are of carefully selected Pyrex glass; and successive mercury columns are hydrostatically coupled with thoroughly outgassed distilled water. Each mercury column height is determined by means of a hairline ruled on a glass slider moving on a meter bar. Mirrors behind the columns prevent parallax. Settings can be read within $\pm 0.1 \mathrm{~mm}$, making a possible over-all error on all eight columns of $\pm 0.8 \mathrm{~mm}$, or about 1.5 $\mathrm{mm}$ maximum. At $1 \mathrm{~atm}$ this amounts to a maximum error of very close to 0.1 percent, which is closer than warranted by other experimental inaccuracies present.

The negative pressure effect of the water column is automatically obtained with each mercury column reading, excepting the two end columns. The end columns terminate in the center of heavy glass bulbs contained in brass protective shields $(C)$ and having a crossseccional area about 250 times that of the manometer tubing. Consequently for a maximum motion of one water column of $50 \mathrm{~cm}$ the change of the end water level will be only $0.2 \mathrm{~mm}$, giving a difference between the levels in the two bulbs of $0.4 \mathrm{~mm}$ of water or $0.03 \mathrm{~mm}$ in mercury, which can be entirely neglected. Temperature-density corrections for the water and mercury are small for ordinary temperature changes and may usually be neglected. 


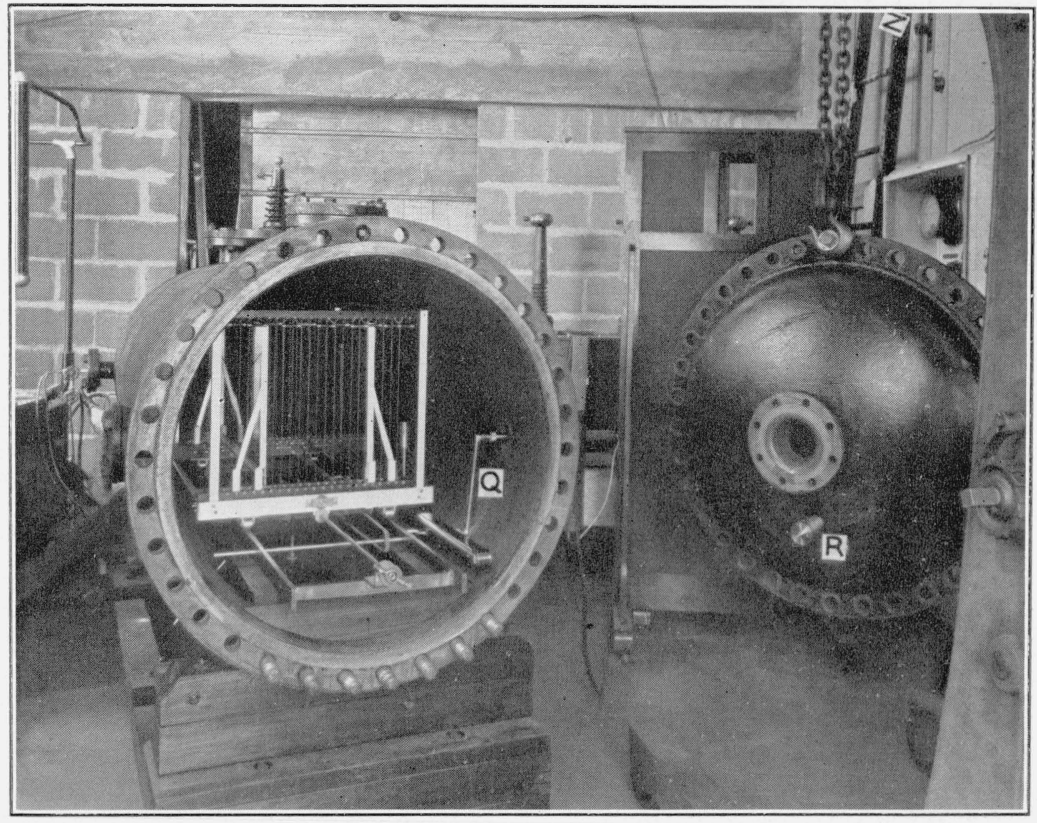

FiguRe 8.-Pressure ionization chamber with rear end removed.

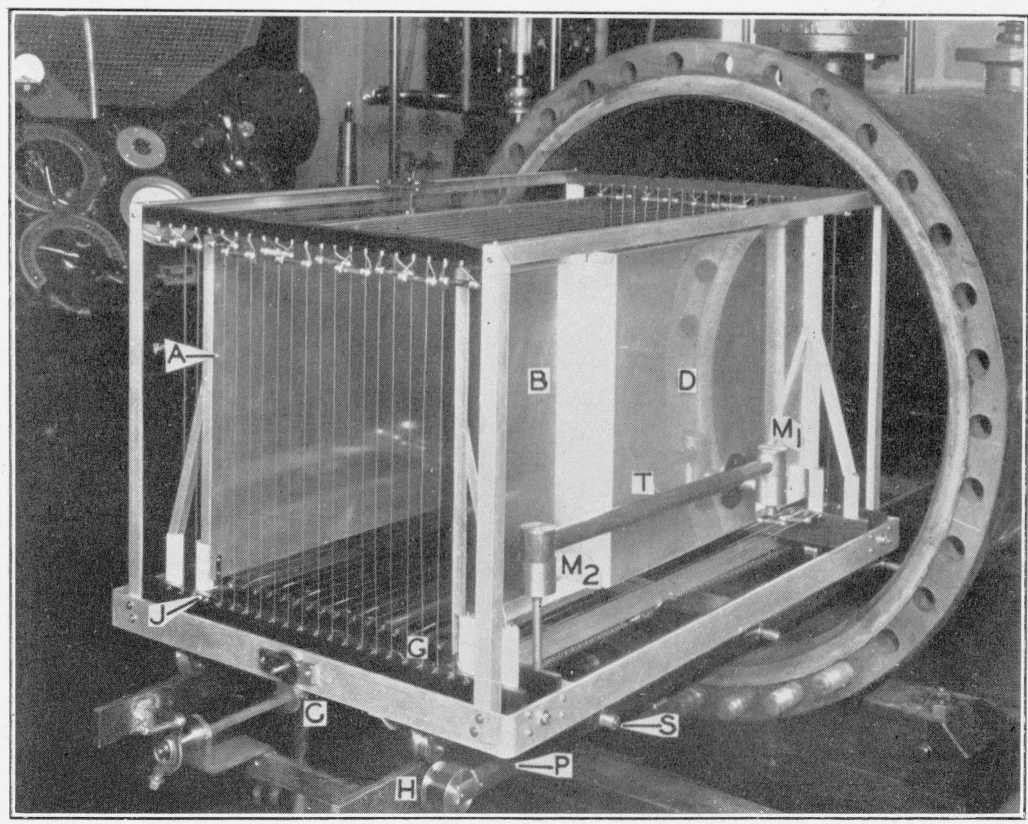

Figure 9.-Ionization chamber electrode system drawn out of rear of pressure chamber. 


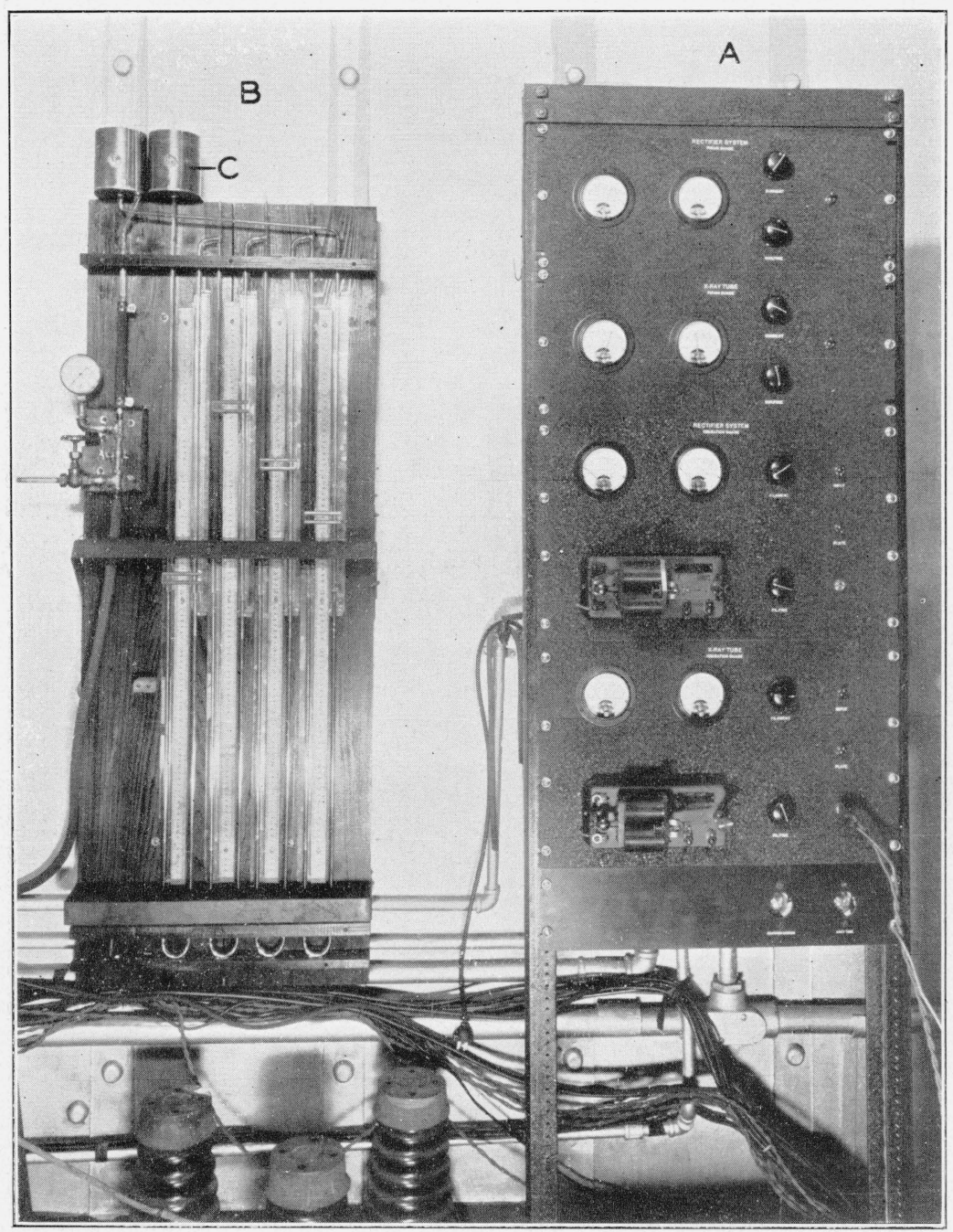

FiguRe 10.-Details of the multiple tube manometer and vacuum gage panel. 
For the calibration of the meter bar and for control purposes a vertical cathetometer is employed. This is easy on the eyes and permits a pressure control within $0.05 \mathrm{~mm}$ of mercury on a single column.

\section{ELECTRODE SYSTEM}

The electrode system is shown in figure 9 in which the entire assembly is pulled partially out of the rear of the chamber. The high-potential plate $(A)$ and collector plate (plus guards) $(B)$ are mounted on cross slides. By means of a pinion and rack (not visible) driven by the gear train $(C)$ the two sets of plates may be moved smoothly toward or away from each other. The motion is transmitted to the lower gear through a sliding collar on a square shaft extending the length of the track and this in turn through a rotary Sylphon seal $(R)$ in the rear of the chamber.

The over-all length of the plates is about $750 \mathrm{~mm}$; the effective length of the collector (including air gap) is $254.0 \mathrm{~mm}$, and each guard plate is about $25 \mathrm{~cm}$ wide. The minimum plate separation is 7.2 $\mathrm{cm}$, and the maximum, $38 \mathrm{~cm}$. The height of the collector being about $35 \mathrm{~cm}$, a plate separation greater than $35 \mathrm{~cm}$ is never ordinarily used since this would cause a loss of some of the ions under conditions where full plate separation is necessary to their full utilization.

In accordance with previous analyses [28, 29], a guard plate width of $25 \mathrm{~cm}$ will permit the use of a plate separation of only 16 to $18 \mathrm{~cm}$ without introducing field distortion at the edges of the collector. For greater separations therefore it is necessary to resort to the method of guarding developed in this laboratory $[30,31]$ for low-voltage ionization chambers.

\section{FIELD CORRECTION}

In this case aluminum guard wires $0.4 \mathrm{~mm}$ in diameter and $2 \mathrm{~cm}$ apart were extended completely around the ionization volume of the chamber except for the small gap $(G)$ near the lower corners to permit the displacement of the plates. The potential of these guard wires was uniformly distributed by insertion of a series of 2-megohm metallized resistors some of which may be seen across the top Bakelite spreader.

To insure full field correction it is important that the potential of the guard wires be uniformly graded between that of the high-poter tial plate and the grounded guard plate. Therefore, for small plate separations, only those guard wires falling between the plates are charged. For this purpose the high potential is applied directly to the collector plate and from there to the guard wires by means of the sliding contact $(J)$. Similarly, the ground is applied directly to the guard plates and to the other end of the guard wires by means of a like contact. These two sliding contacts also serve to tie in the set of guard wires extending along the bottom of the chamber, which otherwise would be isolated.

Since it was planned to use saturation potentials as high as 10,000 $\mathrm{v}$ on the chamber, the possibility of corona from the guard wires had to be tested. At $15,000 \mathrm{v}$ a spark-over occurred at some point within the chamber but below this voltage no effect of corona was detectable with the current-measuring system. 
The entire electrode assembly is mounted on a welded steel track running the full length of the cylinder. The displacement along the track is effected through a sprocket and gear drive operated from without the tank through a pressure-tight rotary Sylphon joint.

\section{STRAY IONIZATION}

To avoid picking up any stray ions or electrostatic disturbances the entire conductor system leading from the collector plate to the electrometer was shielded. The collector itself is shielded by an aluminum cover $(D)$. From there the conductor passes through two swivel joints $\left(M_{1}\right.$ and $\left.M_{2}\right)$ and a section of telescoping tubing $(T)$. From $M_{2}$ the lead passes down to a brushing contact on an insulated rod located centrally in tube $P\left(1 \frac{1}{2} \mathrm{in}\right.$.) extending the length of the track. A $1 / 2$-in. sector of this tube is cut out at the top to permit insertion of the brushing contact. To close this long opening electrostatically, a strip of thin spring steel ( $N$, fig. 8$)$ is stretched along the top and bottom passing over the rollers $(H)$ at the ends, and moves with the chamber so as to always keep the slot covered. A gooseneck connection $(Q)$ leads from the bushing $(S)$ through a pressure-tight seal to the outside of the chamber. The entire electrical system is insulated with highly polished amber and no leakage difficulties have been experienced.

Careful tests were made to detect any stray ionization in this conductor system. The currents being normally measured by a null method, there should be no potential difference between the electrometer leads and the earthed shields. At normal working current sensitivities $\left(10^{-13}\right.$ to $10^{-14} \mathrm{amp} / \mathrm{mm}$ deflection) no evidence of stray ionization currents was found even with an 8-in. entrant beam of X-rays. When a deflection method of measurement is used, the conductor may be at a potential several millivolts different from ground, but even under these conditions no stray ionization has been detected.

However, at the highest sensitivities $\left(5 \times 10^{-15} \mathrm{amp} / \mathrm{mm}\right)$ various difficulties were encountered. Ionization from cosmic rays and alpha-particle contamination produced a slightly unsteady background current amounting to 3 or 4 percent of the total measured current at atmospheric pressure. This was, of course, unavoidable.

Of greater concern was the effect of contact potentials within the insulated system at the very high sensitivities. These gave rise to very uncertain and unsteady stray ionization currents which varied with the plate separation, size of the X-ray beam, etc. These spurious effects were eventually reduced to a workable minimum even at our highest sensitivity. The greatest single source of stray ionization was between the guards and collector electrode where the spacing is only about $0.5 \mathrm{~mm}$. This was largely eliminated by making the three plates out of a single sheet of aluminum, taking care that they were kept in the same relative position as before cutting. In addition, the inside of the tank was scraped and then painted with "Graphite Acid Seal" paint, which we had found by separate tests to establish little contact emf with respect to aluminum or itself.

When using a broad beam at voltages above $360 \mathrm{kv}$, some radiation entered the front of the chamber through the several inches of steel making up the various flanges and supports. This was avoided by 
placing a lead baffle $3 \mathrm{ft}$ square and $1 / 2$ in. thick, on a frame in front of the chamber, with a 3 -in. opening to permit passage of the X-ray beam. The $2 \frac{1}{2}$-in. window at the fore end of the chamber was sealed with $0.5-\mathrm{mm}$ aluminum, which will withstand pressures up to at least $4 \mathrm{~atm}$. In front of this is an electrically operated shutter and a rack for holding a large number of lead and copper filters, which could be shifted in and out of the X-ray beam from within the control room.

The entire assembled chamber was supported on a rigid frame, which, in turn, was mounted on a 20 - $\mathrm{ft}$ track running parallel to the useful X-ray beam. Thus target-diaphragm distances ranging from 2 to $6 \mathrm{~m}$ were obtainable.

\section{DIAPHRAGMS}

Since the cross-sectional area of the limiting diaphragm appreciably affects the accuracy of measurement, it is essential that it be known with an accuracy of \pm 0.1 percent. As pointed out in connection with previous high-voltage X-ray measurements, this is difficult of attainment and was finally reached through the use of hard-gold diaphragms made by plug gage methods [31,32]. More recently it has been found possible to make hard-lead diaphragms by similar methods, relying for their final accuracy upon comparisons with the gold diaphragms. International agreement [33] requires that limiting diaphragms be cylindrical and of such thickness that not more than 0.1 percent of the intensity of the useful transmitted beam passes through the walls of the diaphragm. The use of thick diaphragms necessitates great care in alignment in the beam, since poor alignment reduces the effective area of the opening. Furthermore, at short diaphragm-target distances, a

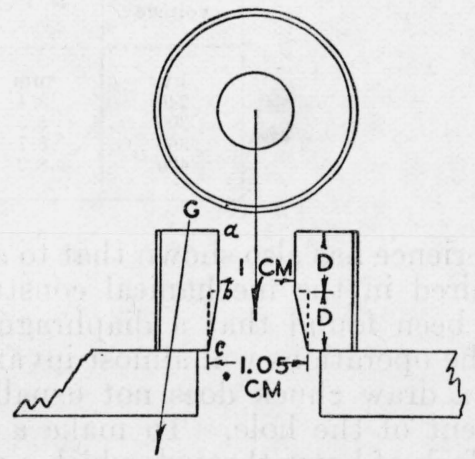
thick diaphragm introduces some uncertainty as to the proper position for placing a thimble chamber under calibration, or as to the application of any inverse-square law corrections.

There has been a tendency to use what we believe to be excessively thick diaphragms in the supervoltage $\mathrm{X}$-ray region; for example, Mayneord [16] used a $3 \mathrm{~cm}$ thickness at $400 \mathrm{kv}$. We, therefore, made some measurements to determine the minimum lead thickness to stop 
off 99.9 percent of the incident radiation. Accordingly, the diaphragms, constructed as shown in figure 11, were made of a thickness $\mathscr{2} D$, where $D$ is the thickness necessary to reduce the radiation to 1 percent of its incident value, and $2 D$ a thickness which will reduce the intensity to substantially less than 0.1 percent. From $a$ to $b$ the orifice is accurately cylindrical and from $b$ to $c$ it is tapered back to such a degree that the cross-sectional area at $c$ is 10 percent greater than at $a$ and $b$. Thus even had the lead been cut away, as indicated by the dotted lines, the diaphragm would not have permitted the passage, through its body, of more than 0.1 percent of the radiation passing through the orifice (assuming complete stoppage through $\mathrm{G}$ ).

Values of $D$ at different voltages were experimentally determined as shown in table 1:

TABLE 1.-Required diaphragm thicknesses for different excitation voltages.

\begin{tabular}{|c|c|c|}
\hline $\begin{array}{c}\text { Tube } \\
\text { voltage }\end{array}$ & $D(1 \%)$ & $\mathrm{D}(0.1 \%)$ \\
\cline { 1 - 2 } $\mathrm{kv}$ & $\mathrm{mm}$ & $\mathrm{mm}$ \\
240 & 3.4 & 6.0 \\
300 & 5.5 & 9.2 \\
360 & 6.7 & 12.0 \\
400 & 8.2 & 16 \\
\hline
\end{tabular}

Experience has also shown that to avoid distortion considerable care is required in the mechanical construction of the lead diaphragms. It has been found that a diaphragm held in a three-jaw chuck for the lathe operations will almost invariably distort after releasing, and use of a draw chuck does not usually permit a sufficiently accurate alignment of the hole. To make a diaphragm $(E)$ we start with a solid block of brass through which a rough hole $(H)$ is bored. This is partially filled with a hard lead alloy ( $\mathrm{Sb}, \mathrm{Cd}, \mathrm{Pb})$, which is forced into place with a rather high sieady pressure (not hammer strokes). The block is then chucked at $C$ and the portions $A-A$ turned off. The lead $(E)$ is then turned down to within about one or two thousandths of an inch of its finished size and cut off at $P$. After being allowed to age for a few days, a standard steel ball is gently forced back and forth through the opening to give it size as well as to burnish its surface.

\section{SATURATION VOLTAGE}

For the saturation voltage it was hoped to use direct current from a valve-rectified alternating-current source. However, after trying all the more common forms of voltage stabilization it was found to be impractical with the present very small capacity current-measuring system. Slow variations were not troublesome but irregular transients were. Several stabilizing devices which worked at a given voltage were impractical under the variable voltage requirements of our work. Large banks of radio $B$ batteries were finally used.

\section{CURRENT MEASUREMENTS}

The current measuring system is shown in figure 12 .

The ionization current is amplified by means of an FP-54 electrometer tube in a balanced circuit of the type first described by Dubridge 
and Brown [34]. The modification of the original Dubridge-Brown circuit shown was suggested to us by Dr. Leo Behr in 1934; this, in common with all modifications since suggested, was designed to minimize the difficulty of balancing the amplifier network, but unfortunately, at the expense of some of the stability inherent in the

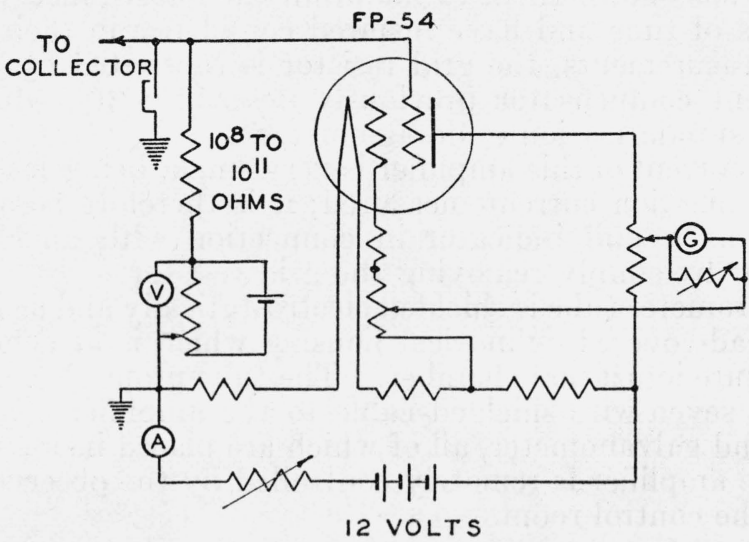

FiguRe 12.-Amplifier circuit.

original. With a galvanometer having a period of $3 \mathrm{sec}$ and a current sensitivity of $5.7 \times 10^{-9} \mathrm{amp} / \mathrm{mm}$ the voltage sensitivity of this system is $5.6 \times 10^{-4} \mathrm{v} / \mathrm{mm}$. With a grid resistor of $2.4 \times 10^{+9} \mathrm{ohms}$, the current sensitivity is $2.3 \times 10^{-13} \mathrm{amp} / \mathrm{mm}$; this sensitivity can be increased up to 50 times this value by increasing the grid resistance proportionately.

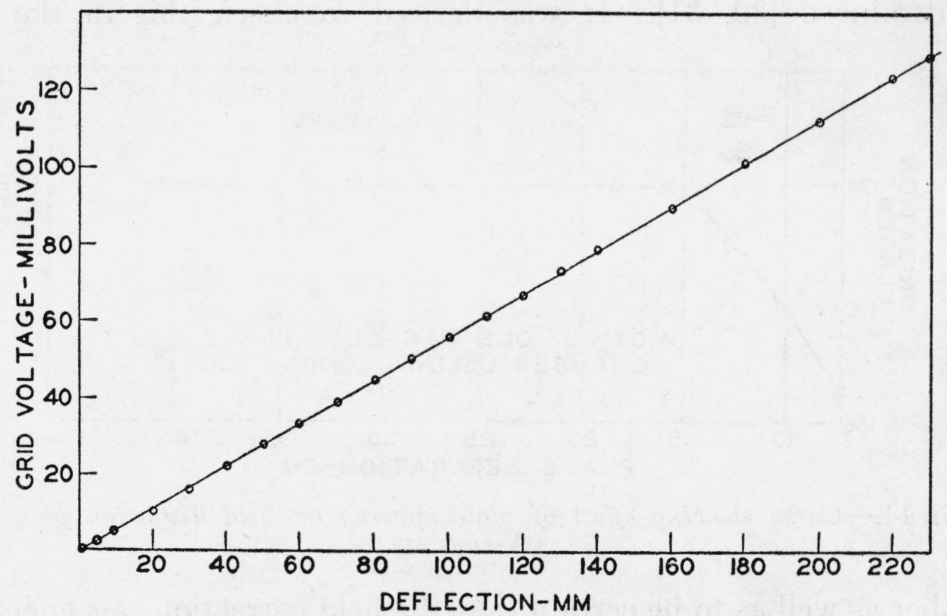

FiguRe 13.-Amplifier calibration curve.

The amplifier is linear to within 1 percent for deflections up to the maximum obtained, as is shown in figure 13.

Comparative current measurements are obtained by direct deflection; for absolute ionization-current measurements the system is used as a null measuring device. The voltage drop across the grid resistor is compensated by means of a potentiometer from the setting of which 
the voltage drop across the grid resistor is determined. If the resistance of the grid resistor is known, the ionization current can be determined. The grid resistors are of the S. S. White type used in this laboratory in a variety of circuits during the past 5 years. Tests of these resistors made in connection with studies of X-ray ionization in liquids [35] has shown them to maintain their resistance values over long periods of time and have inspired confidence in their use. For absolute measurements, the grid resistor is calibrated by an electrostatic current compensator previously described [36], which is now used in the standarization of dosage meters.

The grid current of this amplifier is very small, being less than $10^{-4}$ times the ionization current measured; it is therefore possible to use this sytem as a null indicator in connection with an electrostatic compensator by simply removing the grid resistor.

The electrometer tube is shielded electrostatically and against radiation in a lead-covered cylindrical housing which is attached directly to the pressure ionization chamber. The tube proper is connected by means of a seven-wire shielded cable to the amplifier control panel, batteries, and galvanometer, all of which are placed inside the control room. The amplifier is remotely controlled by the observer from his station in the control room.

\section{IONIZATION-CHAMBER CHARACTERISTICS}

\section{FIELD DISTORTION}

In the 200-kv guarded-field ionization chambers it was found that even with guard wires there was a minimum permissible distance between wires and the chamber ends beyond which error would be introduced $[30,31]$. It was desired to check this in the new

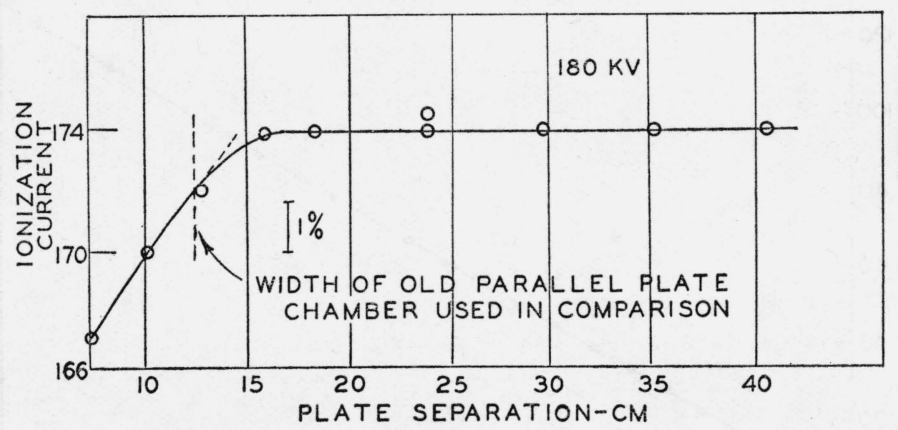

Figure 14.-Curve showing effect of plate spacing on field distortion for 180-kv

chamber as well as to be certain that the field correction was adequate at all plate spacings.

Accordingly, the electrodes were placed as near as possible $(10 \mathrm{~cm})$ to the front of the chamber, set for a minimum separation and the guard wires disconnected from the system. Using an 8-mm beam of $180-\mathrm{kv}$ X-rays the ionization current was measured for several plate spacings up to about $15 \mathrm{~cm}$. Repeating this with the guard wires connected, no detectable difference was found. Measurements of 
the ionization as a function of plate spacings (guard wires connected) are shown in figure 14. Definite saturation is reached at $15 \mathrm{~cm}$, which spacing happens to be about the limit beyond which field distortion should normally be encountered for a $25-\mathrm{cm}$ guard plate width, unless corrected with guard wires. That the curve is flat for spacings greater than $15 \mathrm{~cm}$ proves the efficacy of the guard-wire system.

Comparisons were made between this pressure standard and an early type of free-air standard designed for $180 \mathrm{kv}$ [29]. (Mechanical difficulties prevented the use of our $200-\mathrm{kv}$ guarded-field standard, which, however, agrees with the one used within 0.2 percent.) The same diaphragm and electrometer systems were used for both chambers so that the only factor entering the comparison was the effective plate length. Any further difference would have been due to such sources as spurious scattered radiation, stray ionization, etc. For a plate separation of $12 \mathrm{~cm}$ in the low-voltage standard, and $24 \mathrm{~cm}$ in the pressure standard, the latter indicated about 1.3 percent high. Referring to the curve in figure 14, it is seen that the 12-cm spacing in the old chamber is probably deficient by about 1 percent (as indicated by the ionization current). After making this 1-percent correction, the two chambers agree within the limits of experimental error.

\section{SCATTERING FROM DIAPHRAGM AND PRESSURE-CHAMBER ENDS}

The distance from the aluminim window at the front diaphragm to the collector electrode (in its closest position) is $59 \mathrm{~cm}$, and while an effect of scattering from the thin aluminum entrant window upon the measured ionization seems unlikely, it was important to test therefor. In this connection, it may be stated that the indications of the chamber at high voltages will be unambiguous only if a state of electronic equilibrium exists in the region of the "ionized volume." "Mayneord's [3, 4] and Lauritsen's [5, 6] analyses of this problem are very clear and it is felt that their fundamental conditions for electronic equilibrium must be met.

To test for scattering from the entrant window, the collector was moved as close as possible to the fore end of the pressure chamber and measurements made with the aluminum window, first in the normal position ( $5 \mathrm{~cm}$ from the diaphragm) and then about $30 \mathrm{~cm}$ in front of the diaphragm. The indicated ionization was the same for both cases within limits of measurement. The same was true for similar tests made with a $0.5-\mathrm{mm}$ copper window.

Further tests for scattering from the windows and for electronic equilibrium were effected by making ionization measurements at different positions of the collector plates along the length of the pressure chamber. The plate separation here was great enough to rule out any effect due to the beam divergence. Figure 15 shows a number of such curves at various excitation voltages. The $400-\mathrm{kv}$ curve was made at a chamber pressure of $2 \mathrm{~atm}$. It will be noted that all the graphs are linear within \pm 0.5 percent or better, which agrees with the limits of accuracy at the time the measurements were made. 
Scattering from the entrant window and diaphragm would show up as a sharp rise in the curve for small values of the distance between window and collector electrode. Similarly, scattering from the back of the chamber would cause a flattening of the curve at large values of the distance. Both are clearly absent. The linearity of the curves shows further that electronic equilibrium existed under all conditions of measurement.

Furthermore, from the slope of the curves may be directly obtained the air-absorption coefficients with which it is necessary to correct all measurements. It is to be expected that the curves of figure 15,

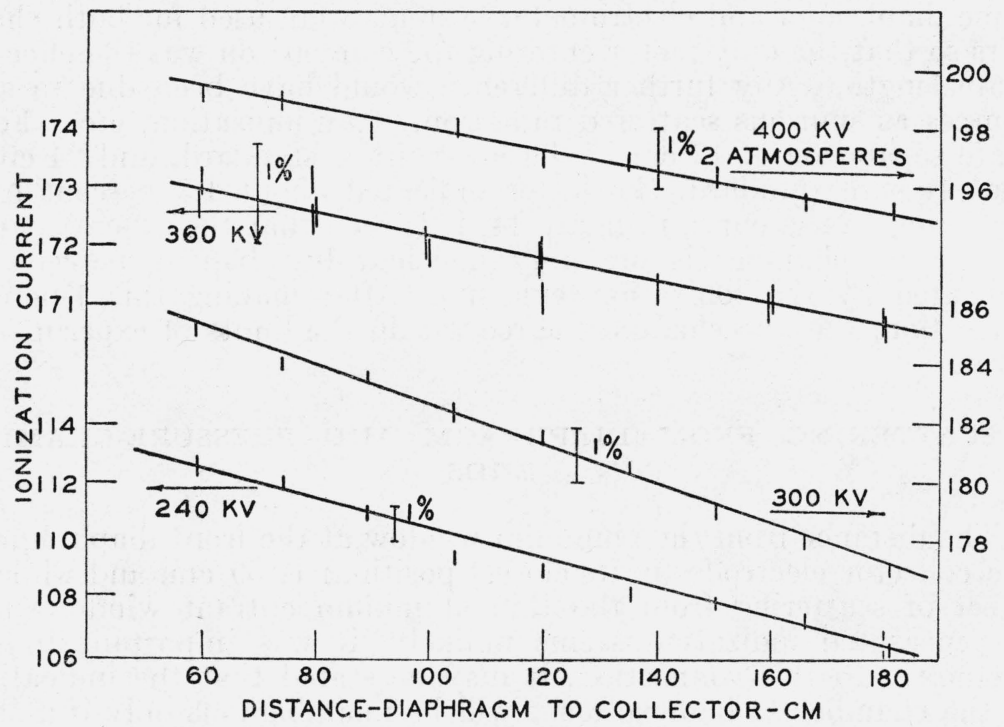

FigURE 15.-Curves showing the ionization as a function of the distance between front diaphragm and collector electrode.

representing absorption of the X-ray beam by air, should be linear within the range studied, since the attenuation is only about 5 percent or less, and hence the change in quality is negligible. Air-absorption coefficients for several radiation qualities are listed in table 2. These may be compared with similar determinations made at lower voltages [37]. The application of air-absorption corrections becomes particularly important at elevated chamber pressures.

TABLE 2.-Air-absorption coefficients

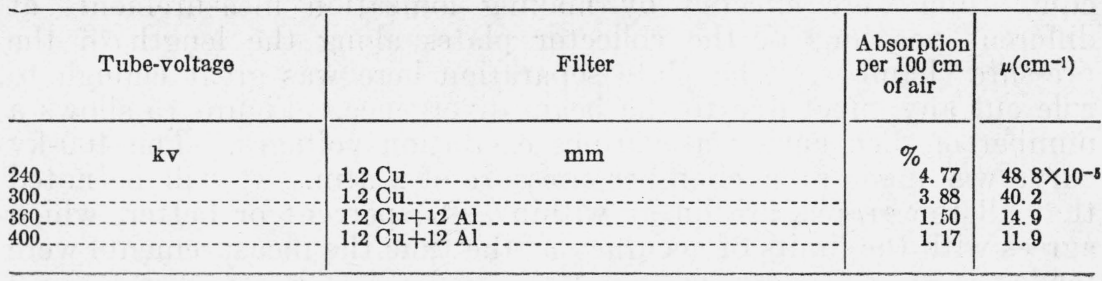




\section{PLATE SEPARATION}

To insure full utilization of the corpuscular emission from the air mass opposite the collector electrode, it is necessary to determine the minimum plate separation which will not cause a reduction in the measured ionization current. A number of such curves at different voltages are given in figure 16 . It will be seen that the minimum spacing is very definite in all cases and increases rapidly with the X-ray excitation voltage. This is decidedly at variance with the investigations cited in the introduction $[16,17]$.

Particular attention is directed to the curves for $400-\mathrm{kv}$ radiation. The curve at atmospheric pressure cannot be said to definitely reach a steady maximum even at the greatest possible plate separation of about $40 \mathrm{~cm}$. However, under a chamber pressure of 2 atm the maximum is definitely reached at a plate separation of about $22 \mathrm{~cm}$. This

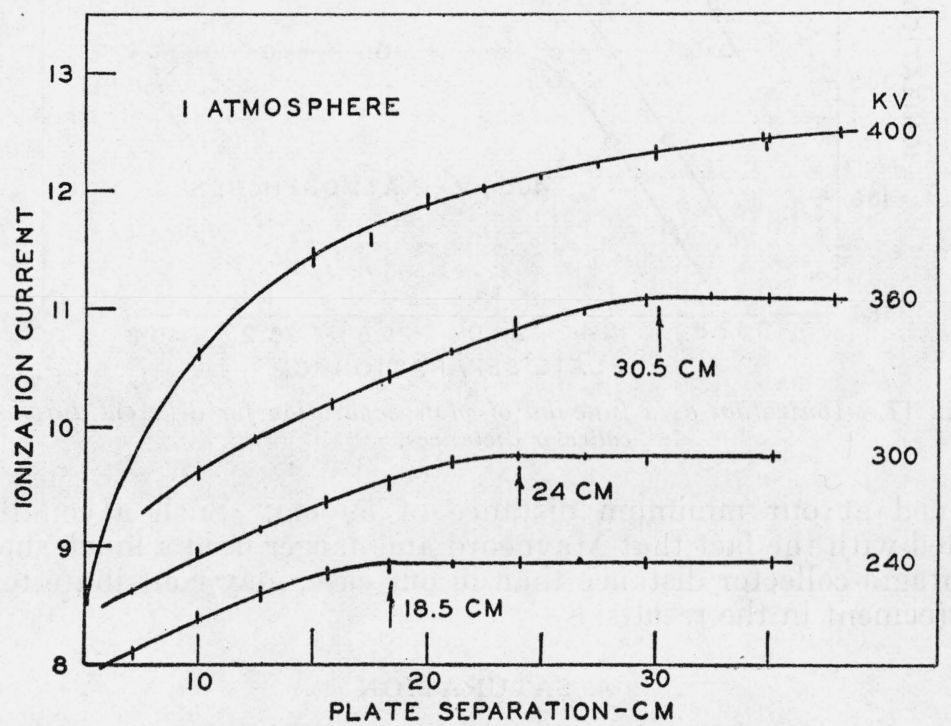

FIGURE 16.-Ionization as a function of plate separation for different $X$-ray voltages.

then fixes the working limits for the particular chamber. At atmospheric pressure, radiations up to $360 \mathrm{kv}$ can be measured; above 360 $\mathrm{kv}$ elevated chamber pressures must be used. It is to be expected that a very considerable reduction in the size of the present chamber could be made by working at a pressure of $5 \mathrm{~atm}$, but that has not been tested.

Failla [14], postulated the formation of an "electron cloud" to explain the limitation of his free-air ionization chamber in gamma-ray measurement. The possibility of a similar condition exists at $400 \mathrm{kv}$, where the scattering is predominantly in the forward direction and would show up as an apparent widening of the beam. This, in turn, would increase the necessary plate separation for electronic equilibrium as the collector-diaphragm distance is increased. Figure 17 shows several plate-separation curves made at $400 \mathrm{kv}$ and 2-atm chamber pressure, for the different collector-diaphragm distances 
shown. There is no evidence whatever of any cloud effect. Similar curves made at atmospheric pressure with $360-\mathrm{kv}$ X-rays likewise showed no cloud effect. This proves only that the cloud effect did not influence the measurements under present conditions. It may well be that it does exist here in principle, and that equilibrium

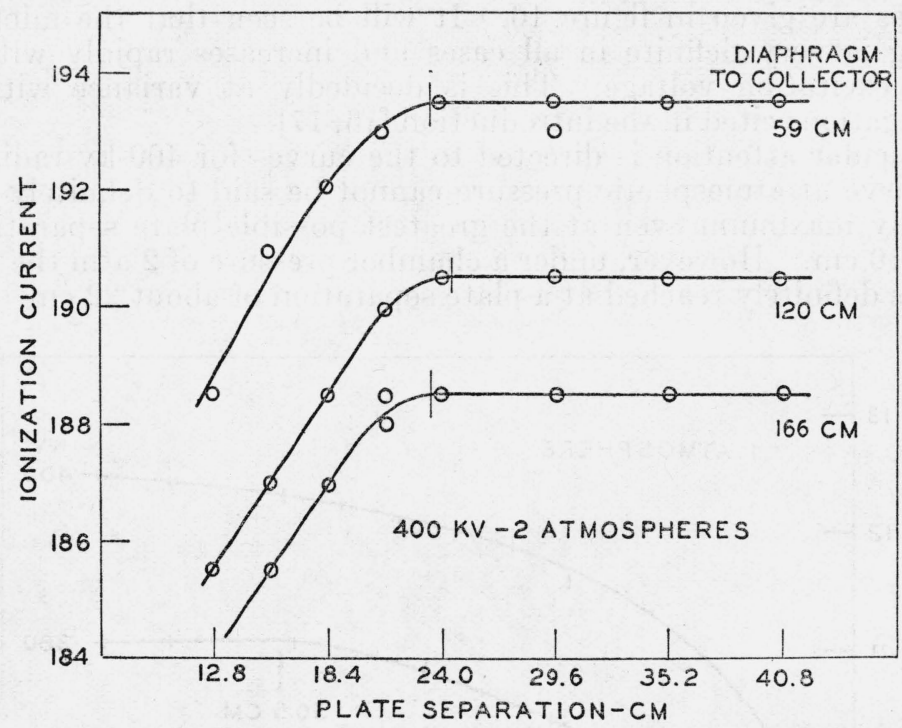

FIgURE 17.-Ionization as a function of plate separation for different diaphragmcollector distances.

obtained at our minimum distance of $59 \mathrm{~cm}$. Such a condition, coupled with the fact that Mayneord and Jaeger used a much shorter diaphragm-collector distance than in our case, may contribute to the disagreement in the results.

\section{SATURATION}

In all of the preceding work, sufficiently high potentials were used across the ionization chamber to insure full or nearly full current saturation. Tests showed that saturation is apparently not as easily obtained as indicated in some earlier work of others. It should be pointed out that "saturation" is not necessarily a definite thing and depends upon the degree of accuracy to which the measurements are made. According to Thomson's theory [42], which has been shown to represent the facts fairly closely, the degree of saturation required will depend upon the precision sought, and the maximum potential will vary as the square root of the precision. Moreover, the potential required for a definite saturation is proportional to the current for the simple case of uniform ionization. While this condition does not obtain in the case of a standard ionization chamber, the saturation voltage does increase with the density of the ionization.

It is not to be expected that radiation quality changes within the range here used should have any great effect upon the shape of the saturation curve. This is shown to be the case in figure 18, which 
gives a group of saturation curves for excitation voltages ranging from 200 to $400 \mathrm{kv}$, but in which the intensities at saturation were all

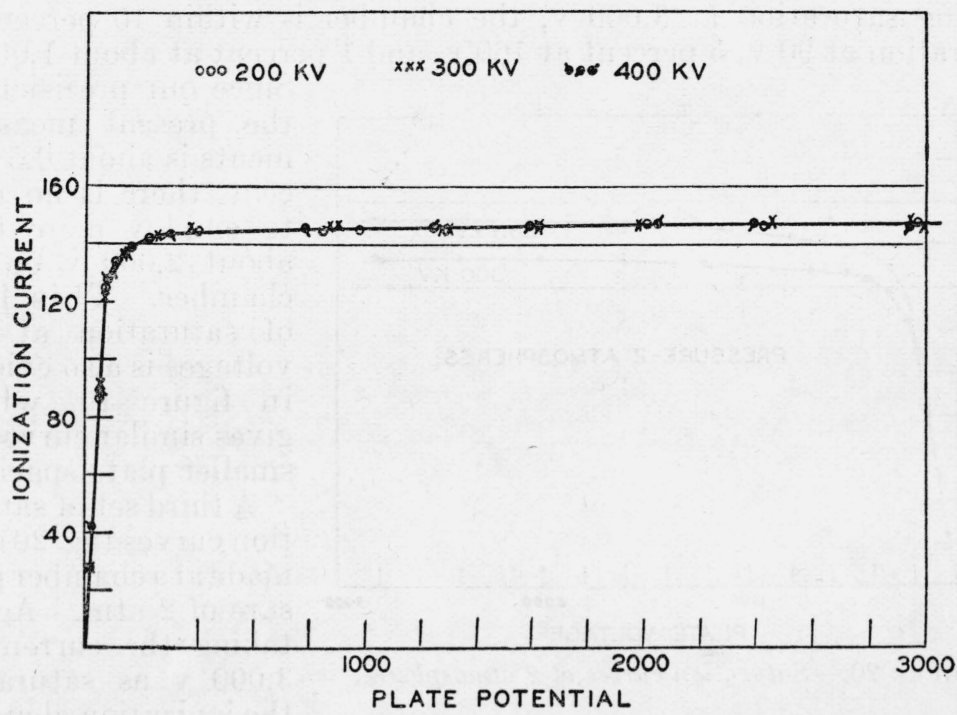

Figure 18.-Saturation curves for plate spacing of $30 \mathrm{~cm}$ and different X-ray voltages.

adjusted to the same value by moving the chamber away from the tube. It is clearly evident that within 0.5 percent all curves are alike and reach saturation at the same voltage.

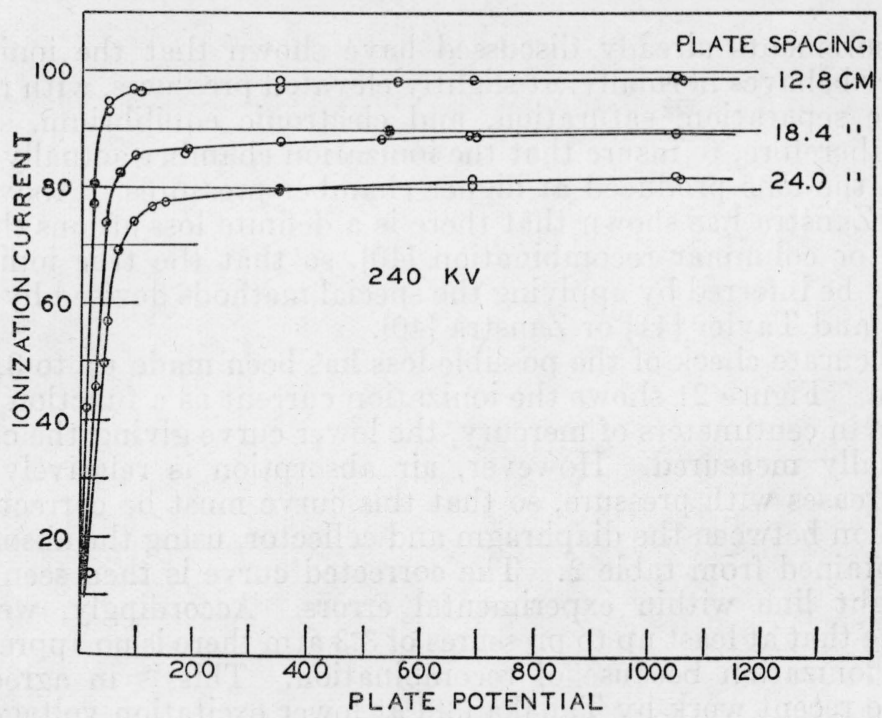

Figure 19.-Saturation curves at $240 \mathrm{kv}$ for different plate spacings.

These curves may be compared with Mayneord's [16], which show saturation at $300 \mathrm{v}$ for a 20 -cm plate spacing, whereas our corresponding 
spacing was $32 \mathrm{~cm}$. The conditions are not exactly comparable, but we do not find his change in form of the curve below saturation. Referring to figure 18 , it is seen that taking a value of 146 as representing saturation at $3,000 \mathrm{v}$, the chamber is within 10 percent of saturation at $90 \mathrm{v}, 5$ percent at $160 \mathrm{v}$, and 1 percent at about $1,000 \mathrm{v}$.

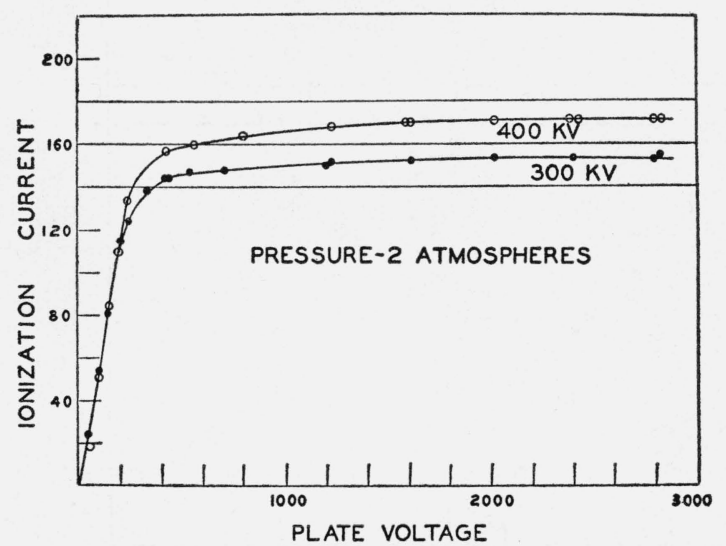

FIGURE 20.-Saturation curves at 2 atmospheres. Since our precision for the present measurements is about 0.5 percent, there is no need to employ more than about $2,000 \mathrm{v}$ on the chamber. This lack of saturation at low voltages is also evident in figure 19, which gives similar curves for smaller plate spacings.

A third set of saturation curves (fig. 20) was made a t a chamber pressure of 2 atm. Again, taking the current at $3,000 \mathrm{v}$ as saturated, the ionization chamber

is within 10 percent of saturation at $400 \mathrm{v}, 5$ percent at $900 \mathrm{v}$, and 1 percent at about $2,000 \mathrm{v}$. These results show the requirement of an approximate doubling of the saturation voltage at double the pressure, as might be expected.

\section{IONIZATION MEASUREMENTS AT ELEVATED PRESSURES}

Measurements already discussed have shown that the ionization chamber behaves normally, at slightly elevated pressures, with respect to plate separation, saturation, and electronic equilibrium. It remains, therefore, to insure that the ionization chamber actually measures all the ions produced at higher chamber pressures. Above 8 or $10 \mathrm{~atm}$ Zanstra has shown that there is a definite loss of ions through volume or columnar recombination [40], so that the true ionization can only be inferred by applying the special methods devised by either Mohler and Taylor [41] or Zanstra [40].

An accurate check of the possible loss has been made up to 3.3-atm pressure. Figure 21 shows the ionization current as a function of the pressure in centimeters of mercury, the lower curve giving the current as actually measured. However, air absorption is relatively large and increases with pressure, so that this curve must be corrected for absorption between the diaphragm and collector, using the absorption data obtained from table 2. The corrected curve is then seen to be a straight line within experimental errors. Accordingly, we may conclude that at least up to pressures of $3.3 \mathrm{~atm}$ there is no appreciable loss of ionization because of recombination. This is in agreement with the recent work by Tanaka [38] at lower excitation voltages. 


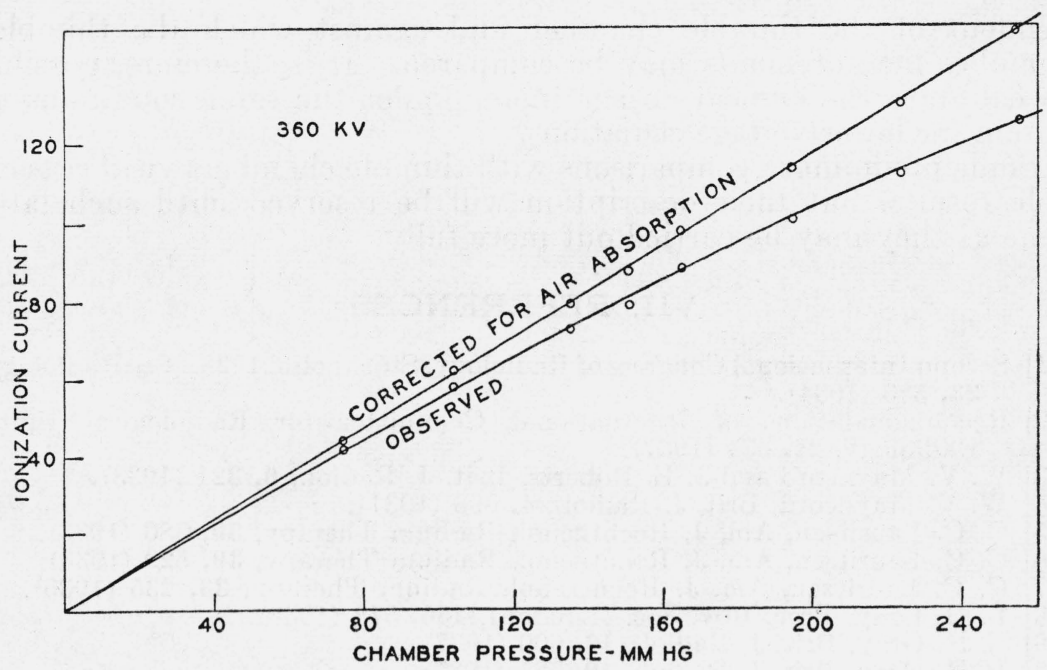

FIGURE 21.-Ionization current as a function of air pressure in chamber.

\section{INVERSE-SQUARE LAW}

Application of the inverse-square law was tested for distances between target and chamber diaphragm ranging from 2.5 to $5.5 \mathrm{~m}$. For this the chamber diaphragm was $1.5 \mathrm{~cm}$ and the tube diaphragm $4 \mathrm{~cm}$ in diameter. The results after correction for air absorption show close adherence to the inverse-square law, so that when necessary we may use it as a basis in calibration work.

\section{GENERAL CONCLUSIONS}

From the measurements described above, we may conclude that it is feasible to construct a standard free-air ionization chamber for the measurement of supervoltage X-rays, although our basis for this conclusion rests upon physical factors which differ decidedly from those of Jaeger [17], who reached the same conclusion. In particular, it is found to be possible to measure radiations of excitation potentials up to $360 \mathrm{kv}$ with a free-air chamber of moderate plate separation $(30 \mathrm{~cm})$ at atmospheric pressure. For higher excitation voltages the ionization chamber may be kept within practical size limits by using it at slightly elevated pressures.

It appears, from these results, possible to construct an ionization chamber of very much smaller dimensions than herein used. Our own chamber was made its present size to permit the unhampered exploration of supervoltage measurements up to well over a million volts and possibly into the gamma-ray region. The results thus far indicate fair promise for extension to higher excitation voltages than used bere.

Through the use of specially constructed X-ray generating equipment it is possible to make free-air ionization measurements in the supervoltage region with an accuracy comparable with that obtained in the high- and low-vol tage region. There is thus provided a means for measuring the international roentgen by a means wholly inde- 
pendent of the thimble chamber and against which the thimblechamber measurements may be compared. It is, therefore, possible to calibrate the clinical dosage meter under the same conditions as obtain for lower voltage radiations.

Some preliminary comparisons with thimble chambers yield reasonable results, but their description will be reserved until such later time as they may be carried out more fully.

\section{REFERENCES}

[1] Second International Congress of Radiology, Stockholm, 1928. See Radiology, 23, 580 (1934).

[2] Recommendations of International Committee for Radiological Units. Radiology, 29, 634 (1937).

[3] W. V. Mayneord and J. E. Roberts, Brit. J. Radiol., 6, 321 (1933).

[4] W. V. Mayneord, Brit. J. Radiol., 4, 693 (1931).

[5] C. C. Lauritsen, Am. J. Roentgenol. Radium Therapy, 30, 380 (1933).

[6] C. C. Lauritsen, Am. J. Roentgenol. Radium Therapy, 30, 529 (1933).

[7] C. C. Lauritzen, Am. J. Roentgenol. Radium Therapy, 33, 235 (1935).

[8] L. H. Gray, Proc. Roy. Soc. (London), 156, 578 (1936).

[9] L. H. Gray, Brit. J. Radiol., 10, 600 (1937).

[10] L. H. Gray, Brit. J. Radiol., 10, 721 (1937).

[11] G. C. Laurence, Can. J. Research, A15, 67 (1937).

[12] Report of Committee on Standardization of X-ray Measurements, Radiology, 22, 289 (1934) and 26, 634 (1936).

[13] G. Failla and P. Henshaw, Radiology, 17, 1 (1931).

[14] G. Failla and L. D. Marinelli, Am. J. Roentgenol. Radium Therapy, 38, 312 (1937).

[15] L. S. Taylor and G. Singer, Radiology, 15, 637 (1930).

[16] W. V. Mayneord and J. E. Roberts, Brit. J. Radiol., y, 158 (1934).

[17] R. Jaeger, Physik. Z., 35, 841 (1934).

[18] G. W. C. Kaye, Strahlentherapie, 56, 608 (1936).

[19] G. W. C. Kaye, Proc. Roy. Soc. (London) [A], 161, 564 (1937).

[20] D. H. Sloan, Phys. Rev., 47, 62 (1935).

[21] M. A. Tuve, L. R. Hafstad, and O. Dahl, Phys. Rev., 48, 315 (1935). (See this paper for abundant references to their own and other earlier work.)

[22] M. A. Tuve, O. Dahl, and L. R. Hafstad, Phys. Rev., 48, 241 (1935).

[23] T. R. Folsom, Rev. Sci. Instr., $\%$, 406 (1936).

[24] W. D. Coolidge, J. Frank. Inst., 202, 693 (1926).

[25] M. A. Tuve, L. R. Hafstad, and O. Dahl, Naturwissenschaften, 24, 625 (1936).

[26] L. S. Taylor, Radiology, 16, 893 (1931).

[27] C. H. Meyers and R. S. Jessup, BS J. Research, 6, 1061 (1931), RP324.

[28] G. Failla, Am. J. Roentgenol. Radium Therapy, 21, 437 (1930).

[29] L. S. Taylor, Radiology, 14, 372 (1930).

[30] L. S. Taylor and G. Singer, Radiology, 15, 637 (1930).

[31] L. S. Taylor and G. Singer, Radiology, 26, 322 (1936).

[32] L. S. Taylor and C. F. Stoneburner, BS J. Research, 9, 769 (1932), RP505.

[33] Roentgen Ray Standards and Units, Am. J. Roent., 31, 815, (1934).

[34] L. A. Dubridge and H. Brown, Rev. Sci. Instr., 14, 532 (1933).

[35] L. S. Taylor, J. Research NBS, 1\%, 557 (1936), RP927.

[36] L. S. Taylor, BS J. Research, 6, 807 (1931), RP306.

[37] L. S. Taylor and G. Singer, Radiology, 17, 104 (1931).

[38] H. Tanaka, Nippon Suugaku Buturigakkwai-Kizi, 10, No. 1 Supplement.

[39] J. E. Rose, Rev. Sci. Instr., 8, 130 (1937).

[40] H. Zanstra, Physica, 2, 817 (1935).

[41] F. L. Mohler and L. S. Taylor, J. Research NBS, 13, 659 (1934), RP733.

[42] J. J. Thomson, Conduction of Electricity in Gases, Cambridge (1903).

Washington, January 15, 1938. 